\title{
Modelling free gas overpressure in peat layers
}

\author{
Stefano Muraro ${ }^{1, *}$, and Cristina Jommi ${ }^{1,2}$ \\ ${ }^{1}$ Delft University of Technology, Stevinweg 1 / PO-box 5048, 2628 CN, Delft, the Netherlands \\ ${ }^{2}$ Politecnico di Milano, piazza Leonardo da Vinci 32, 20133, Milano, Italy
}

\begin{abstract}
The paper assesses fully coupled hydro-mechanical numerical approaches developed for unsaturated soils to model the effect of free gas overpressure on the response of peat layers. A simple linear model is used for the soil skeleton, however, the global response is non-linear due to changes over time of the compressibility of the solid skeleton over the compressibility of the fluid, and solubility of gas in water. The overpressure generated in foundation peat layers by barometric pressure oscillations is modelled, and the results are compared to literature data. The development of pore overpressure upon unloading is analysed as a function of the soil skeleton compressibility, and the consequences on the average stress acting on the soil skeleton are discussed.
\end{abstract}

\section{Introduction}

Assessment of transport and flood defence infrastructure founded on peat is challenging for geotechnical engineers due to the presence of abundant organic fraction made of partially decomposed roots, stems and fibres in the peats matrix.

In the recent years, concerns arose from the decomposition of the organic matter which tends to saturate the pore fluid with gas species as $\mathrm{CH}_{4}, \mathrm{H}_{2} \mathrm{~S}$ and $\mathrm{CO}_{2}$. When the concentration of these gases exceeds the equilibrium solubility, dissolved gases can exsolve upon anthropogenic actions as excavation and dewatering, and environmental loads as temperature rise and atmospheric pressure change as schematised in Fig. 1. Gas bubbles trapped in the basal peat were observed by Den Haan and Kruse [1] in the Wilnis dyke by means of CPT camera sounding and, more recently, by Zwanenburg [2], with gas bubbles venting upon dewatering during the field trial test at Uitdam on the Lake Markermeer, north of Amsterdam.

The presence of gas bubbles trapped in peat layers is confirmed by pore pressure measurements in buried closed piezometers.

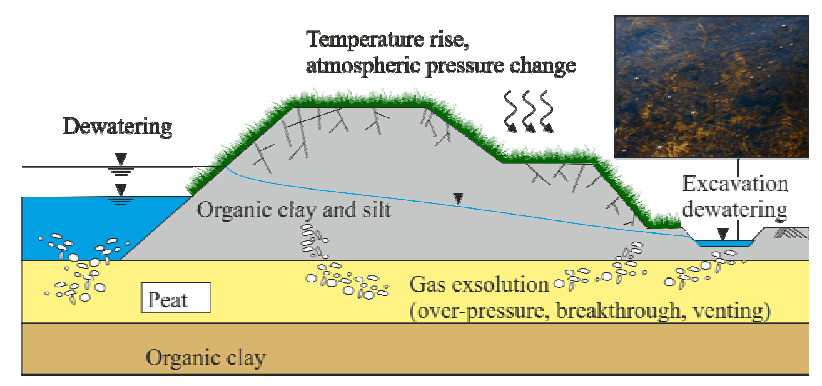

Fig. 1. Schematic representation of gas exsolution occurring in the foundation peat layer and interaction with external loads.
Worth mentioning, Vonk [3] observed water spouting out from probing holes after pulling out the penetrometer during a series of CPT tests at the Bleiswijk polder near Rotterdam. Standpipes installed in the holes through the basal peat layer showed a water level raising $2.5 \mathrm{~m}$ above the ground surface, which was ascribed to the presence of a cluster of biogenic gas bubbles accumulated in the peat layer over years.

Cyclic changes in pore water pressure in peat bogs have been correlated to the natural oscillations of the atmospheric pressure around its average value, 0.1013 MPa ([4-8]). Of particular interest, systematic higher pore pressure in closed piezometers than in open vented standpipes was measured at decreasing atmospheric pressure, which was attributed to the exsolution and expansion of dissolved and free gas in the peat matrix ([5]). Fig. 2 reports the difference in pore pressure measured by non-vented pressure transducers and open piezometers compared to the atmospheric pressure oscillation at three different depths in a fen peatland in the southern Québec in Canada. The data in Fig. 2 show the typical mirror effect in the oscillation of the atmospheric pressure and the variation of the excess pore pressure.

Despite the magnitude of the excess pore pressure being limited to few $\mathrm{kPa}$, its effect on the response of earth embankments on peats should not be disregarded, as shown by Acharya et al. [9] and Jommi et al. [10] in dedicated experimental studies. A fully coupled hydromechanical numerical approach is proposed here to quantify the effects of gas on the pore liquid phase response. The sensitivity to gas exsolution of the soil response is evaluated as a function of the ratio between the volumetric stiffness of the pore fluid and the soil skeleton.

\footnotetext{
Corresponding author: S.Muraro@tudelft.nl
} 


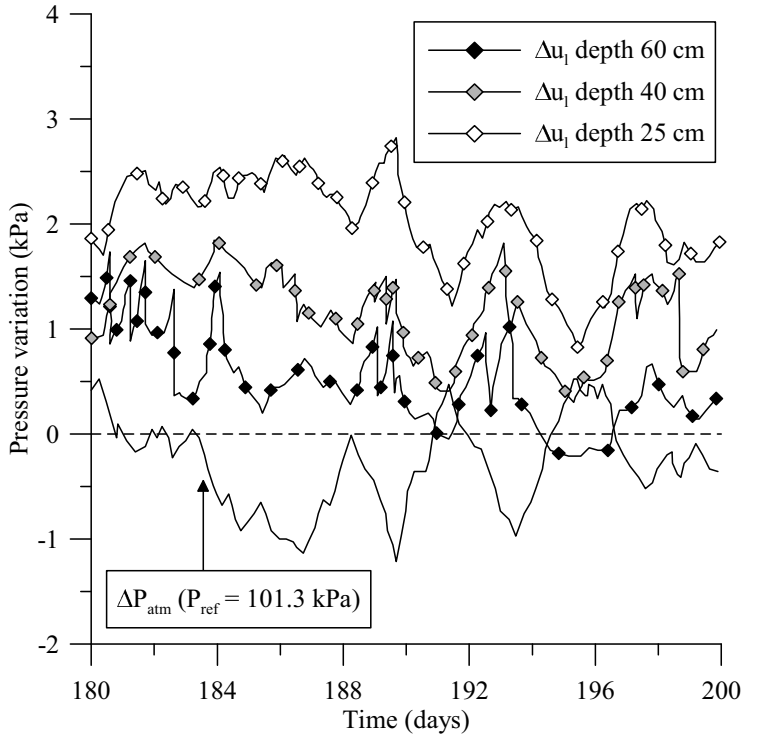

Fig. 2. Variation of the excess pore pressure at three different depths and deviation of the atmospheric pressure from 101.3 $\mathrm{kPa}$ (re-drawn from Kellner et al. [5]).

\section{Finite element model}

Fully coupled two-phase flow with hydro-mechanical coupling was simulated on a 2D plain strain model with CODE_BRIGHT ([11]). For the sake of simplicity, an elastic model is adopted for the soil mechanical behaviour. The assumption does not hinder the validity of the results, as unloading stress paths are of relevance in triggering gas exsolution. The typical soil profile at the Markermeer, consisting of a peat layer underneath a surficial clay cover is considered (Fig. 3). The material properties of relevance for the coupled response are reported in Table 1. Two different values of the watersoil volumetric stiffness are considered $\left(K_{w} / K\right)$.

Table 1. Material properties of relevance in the analyses.

\begin{tabular}{|l|c|c|}
\hline \multicolumn{1}{|c|}{ Parameters } & Symbol & Value \\
\hline $\begin{array}{l}\text { Ratio between water and soil } \\
\text { skeleton stiffness }\end{array}$ & $K_{w} / K$ & $89-667$ \\
\hline $\begin{array}{l}\text { Saturated hydraulic } \\
\text { conductivity }\end{array}$ & $\begin{array}{c}k_{\text {sat }} \\
\text { (isotropic) }\end{array}$ & $\begin{array}{c}7.4 \mathrm{e}-7 \mathrm{~m} / \mathrm{s} \text { peat } \\
1 \mathrm{e}-9 \mathrm{~m} / \mathrm{s} \text { clay }\end{array}$ \\
\hline
\end{tabular}

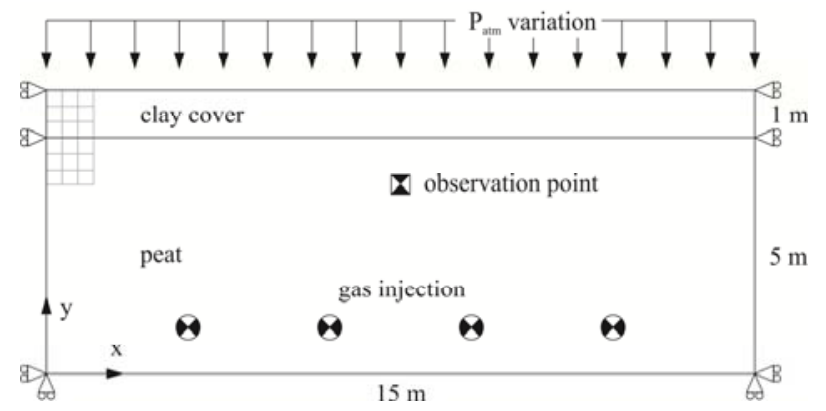

Fig. 3. Geometry of the problem.
The retention behaviour was characterised in a dedicated experimental activity by Trivellato [12]. The Soil Water Retention Curve (SWRC) and the liquid phase relative permeability, $k_{r l}$, of the peat are displayed in Fig. 4 and Fig. 5. A van Genuchten model ([13]) is adopted to fit the experimental data, with $\alpha=350 \mathrm{kPa}$ and $\lambda=0.25$.

$$
\begin{gathered}
S_{r}=\left[\left(1+\frac{\psi}{\alpha}\right)^{1 /(1-\lambda)}\right]^{-\lambda} \\
k_{r l}=\sqrt{S_{r}}\left[1-\left(1-S_{r} 1 / \lambda\right)^{\lambda}\right]^{2}
\end{gathered}
$$

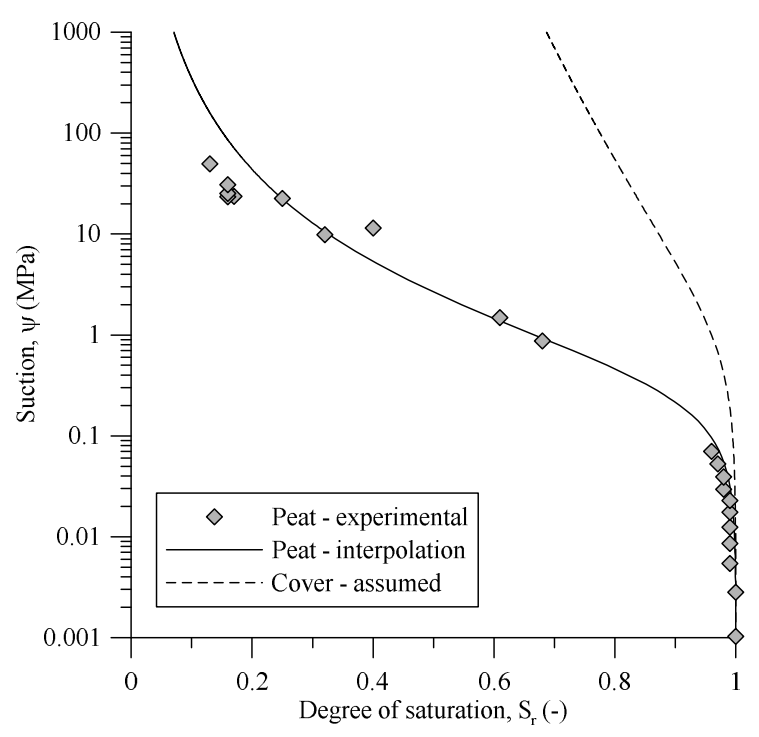

Fig. 4. SWRC adopted in the numerical analyses.

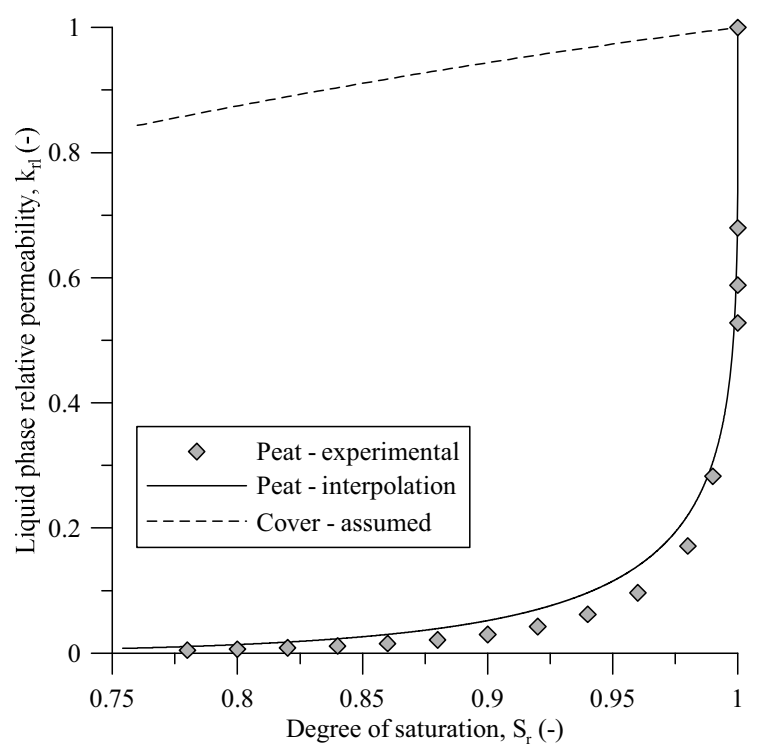

Fig. 5. Liquid phase relative permeability adopted in the numerical analyses. 
The gas phase relative permeability, $k_{r g}$, is assumed to follow the relationship

$$
k_{r g}=1-k_{r l}
$$

The retention properties of the upper cover were chosen in order to limit the escape of the gas entrapped in the lower peat layer, as shown in Fig. 4 and Fig. 5.

To simulate biogenic gas production, the analyses included the following steps:

- initialisation of the geostatic stress conditions;

- injection of $4.7 \mathrm{~kg}$ of $\mathrm{CH}_{4}$ in the peat layer;

- equalisation of gas pressure and gas distribution;

- variation of the atmospheric pressure at the ground surface $\left(\mathrm{P}_{\mathrm{atm}}\right.$ variation in Fig. $\left.7(\mathrm{a})\right)$.

Two sets of analyses are conducted to mimic the field observations. In the first set, the gas phase is not included, which reproduces the field observations from open vented standpipes. The second series accounts for the presence of entrapped gas in the peat layer to reproduce field measurements with non-vented pore pressure piezometers. Gas was injected through four internal nodes in the lower part of the layer as shown in Fig. 3, allowing for drainage of the necessary amount of water from the top boundary of the model.

The variation of the atmospheric pressure replicates the data by Kellner et al. [5] reported in Fig. 2. The properties of methane (density, viscosity, diffusivity and solubility) and those of water were assigned for a reference temperature of $20^{\circ} \mathrm{C}$, which was kept constant throughout the analyses.

\section{Numerical results}

The contour plots of the gas pressure and the degree of saturation for the liquid phase during the gas injection is reported in Fig. 6. Due to localised, instead of diffused, gas injection, some time is needed for the gas to distribute within the peat layer and for the gas pressure to equalise. At the end of the equalisation time, the gas eventually accumulates under the upper cover layer, as observed in peat layers in the field. The degree of saturation at the end of the equalisation step attains a value of about 0.95 .

After equalisation, the atmospheric pressure acting on the ground surface is varied with time as in Fig 2. The numerical results are discussed with reference to the pore liquid pressure, $u_{l}$, the dissolved gas fraction, $\chi_{g}$, and the excess pore liquid pressure, $\Delta u_{l}$, computed as the difference between the liquid pressure in the presence and in absence of gas in the pore fluid. This simulation strategy allows for a comparison of the numerical results with the field measurements reported by Kellner et al. [5]. All the plots refer to an observation point located in the peat layer, $1 \mathrm{~m}$ below the cover (Fig. 3).

The pore liquid pressure in the peat layer is shown in Fig. 7(b) for the case of $K_{w} / K=667$. The variation of the pore liquid pressure is dampened by the presence of gas, which increases the compressibility of the pore fluid ([10]).
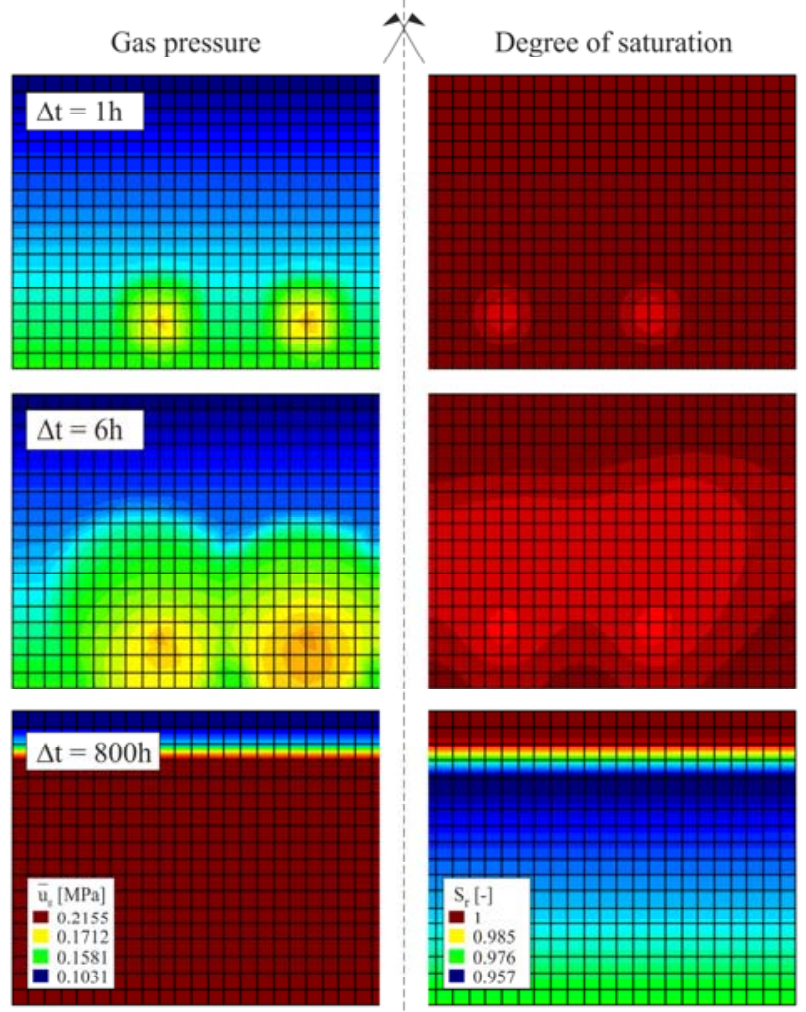

Fig. 6. Contour plots of the absolute gas pressure and the degree of saturation during gas injection and after equalisation.

The results in Fig. 7(b) clearly show that the pore liquid pressure remains higher than that of the fully saturated soil upon a decrease in the atmospheric pressure. The opposite is observed when the atmospheric pressure increases.

Fig. 8 reports the dissolved gas fraction defined according to the Henry's law as

$$
\chi_{g}=\frac{\bar{u}_{g}}{H} \frac{M_{g}}{M_{w}}
$$

where $\bar{u}_{g}$ is the absolute gas pressure, $H$ is the Henry's constant of methane equal to $3638 \mathrm{MPa}\left(\mathrm{T}=20^{\circ} \mathrm{C}\right)([14])$, $M_{g}$ and $M_{w}$ are the molecular masses of methane 0.016 $\mathrm{kg} / \mathrm{mol}$ and of water, $0.018 \mathrm{~kg} / \mathrm{mol}$, respectively.

The comparison between Fig. 7 and Fig. 8 indicates that the occurrence of gas exsolution, promoted by the drop in the liquid pressure, contributes to the total change in pore liquid pressure by increasing the fluid compressibility. Fig. 8 also reveals a dependence of the amount of gas exsolved on the volumetric stiffness ratio, $K_{w} / K$, which will be further discussed in the following. The results in Fig. 7 allow estimating the excess pore liquid pressure due to the presence of free gas in the pore fluid upon atmospheric pressure changes.

As shown in Fig. 9, the coupled formulation is capable to reproduce the mirror effect in the oscillation of the pore liquid pressure compared to the atmospheric pressure, as observed in Fig. 2 from field measurements. 

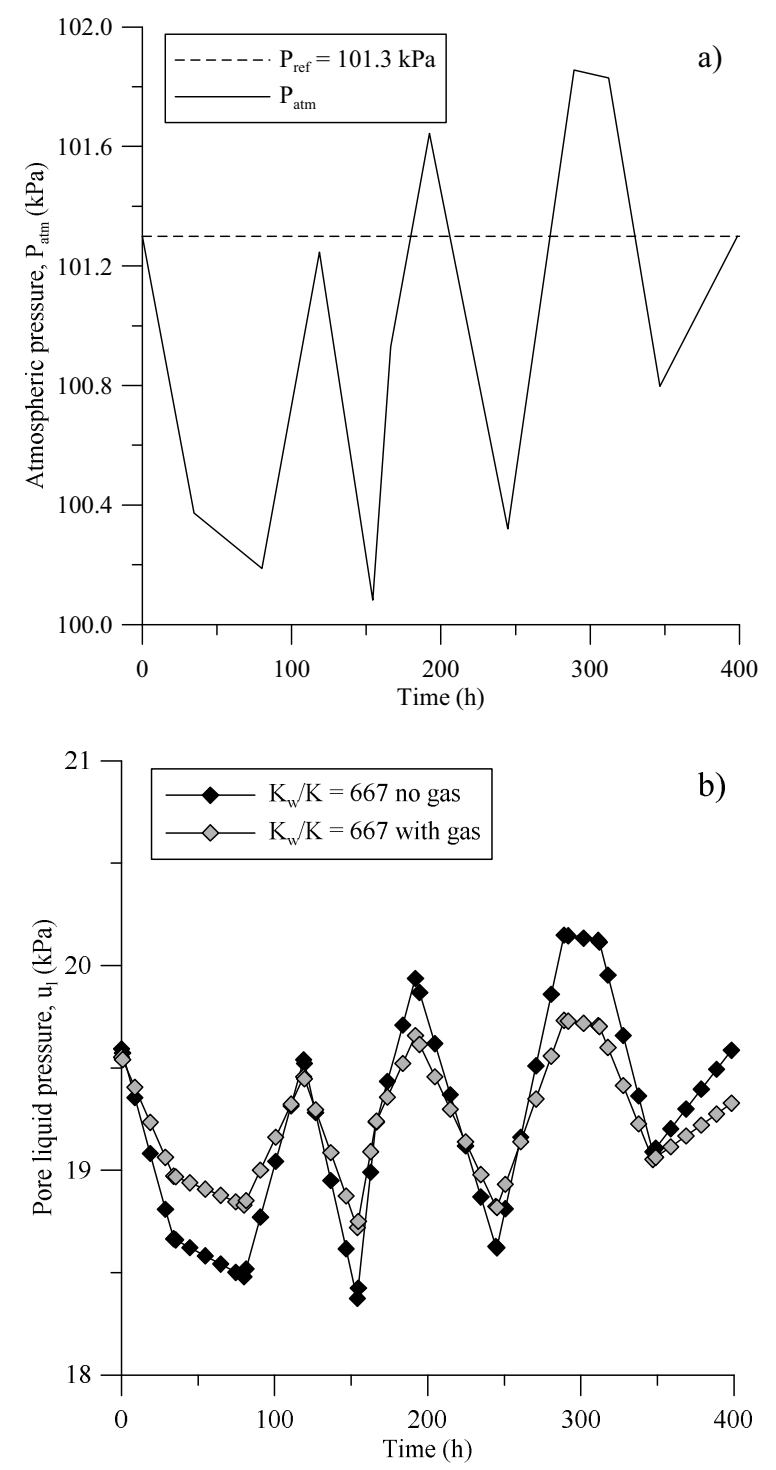

Fig. 7. Evolution of the atmospheric pressure imposed to the ground surface (a), and the corresponding pore liquid pressure for a soil layer with and without gas (b).

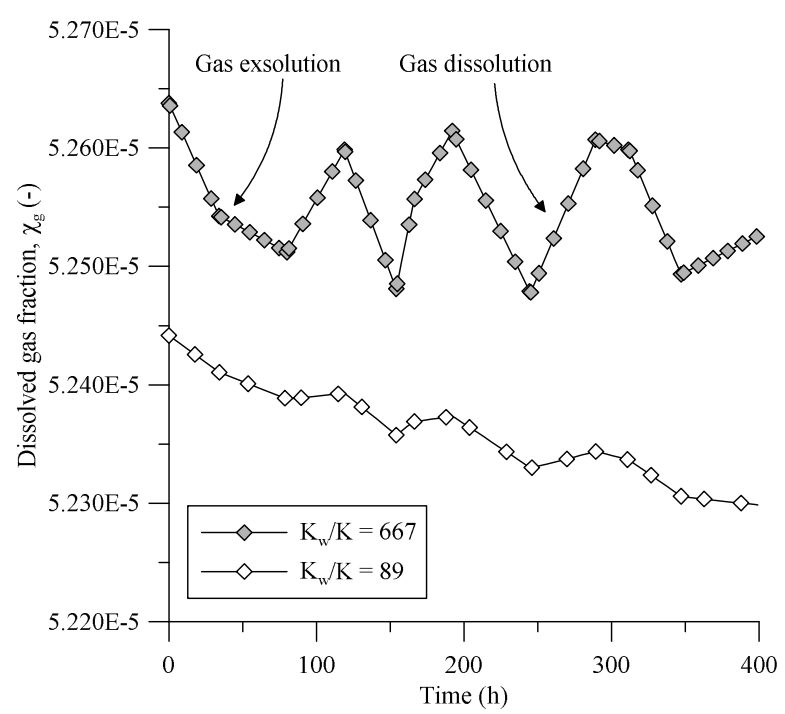

Fig. 8. Dissolved gas fraction in the pore fluid upon variation of the atmospheric pressure.

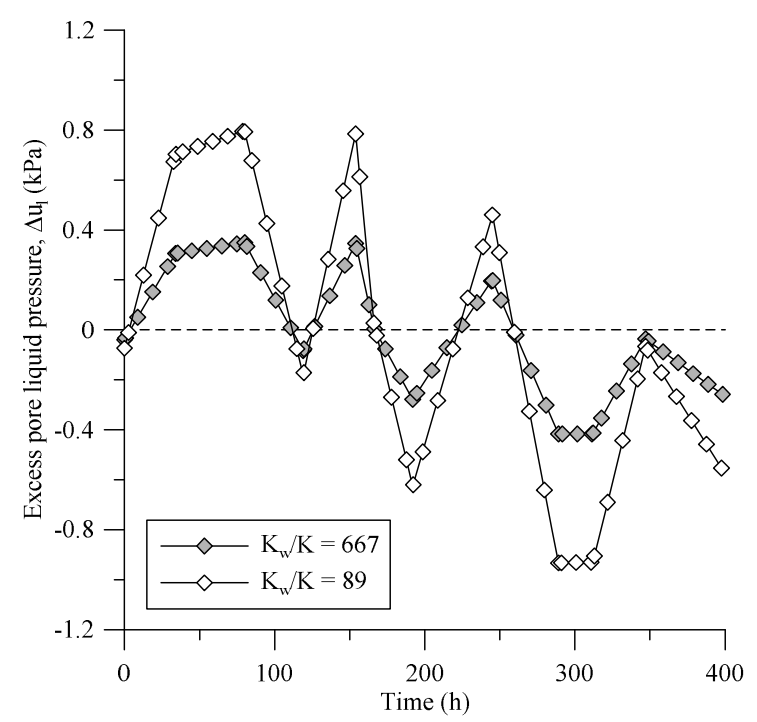

Fig. 9. Excess pore liquid pressure due to free gas in the pore fluid upon variation of the atmospheric for two different values of water-soil volumetric stiffness.

\section{Discussion}

\subsection{Concomitant factors to gas overpressure}

The maximum excess pore liquid pressure displayed in Fig. 9 is about $0.8 \mathrm{kPa}$ for a low relative stiffness ratio $K_{w} / K$ and $0.4 \mathrm{kPa}$ in the case of higher $K_{w} / K$. The order of magnitude found in the field by Kellner et al. [5] and displayed in Fig. 2 for the same atmospheric pressure oscillation is about $3 \mathrm{kPa}$. Very good qualitative agreement between numerical results and field observation is achieved. However, some aspects not accounted for in the proposed numerical analyses are worth mentioning, which may contribute to explain the observed quantitative differences.

Seasonal changes in temperature seem to be one of the major contributing factors to high excess pore pressure often measured during the warmer months. Acharya et al. [9] reported field measurements and laboratory data confirming liquid pressure in excess of the hydrostatic values due to thermal gas exsolution and expansion in peat (i. e. decrease in the gas solubility with increasing temperature). A pore liquid pressure increase of $11 \mathrm{kPa}$ was found resulting from an increase in temperature of $6^{\circ} \mathrm{C}$.

Temperature increase intensifies the biological activity, hence promoting faster peat decomposition. Higher rate of production of $\mathrm{CH}_{4}, \mathrm{H}_{2} \mathrm{~S}$ and $\mathrm{CO}_{2}$ may supersaturate the pore fluid, which promotes additional gas exsolution.

Eventually, gas expansion and coalescence create local overpressure zones with gas bubbles entrapped in the peat matrix. These zones will experience liquid pressure notably higher than that of the adjacent soil, which results in gas bursting when a pressure threshold across the blocking bubbles is reached ([5]). Evidence of gas bursting is shown in Fig. 2 by a series of sudden drops in the measured pore pressure, which is 
accompanied by gas release, as confirmed by numerous authors ([4-7], [9]).

\subsection{Soil sensitivity to gas exsolution}

The previous numerical results suggest a dependence of the pore liquid pressure change (Fig. 7) and the dissolved gas fraction (Fig. 8) on the volumetric stiffness ratio $K_{w} / K$. The influence of the soil skeleton compressibility on the sensitivity of soils to gas exsolution is further investigated with a single soil element model. To model the mechanical behaviour, the mean soil skeleton stress, $\hat{p}$, is chosen as stress variable ([15])

$$
\hat{p}=p-u_{l}-\left(l-S_{r}\right)\left(u_{g}-u_{l}\right)
$$

where $p$ is the mean total stress and $u_{g}$ is the gas pressure. Non-linear isotropic elasticity is considered with a constant slope of the isotropic unloadingreloading line (ISO-URL), $\kappa$. Finite compressibility of the fluid and gas exsolution-dissolution and expansion are accounted for in the water mass balance and gas mass balance discretised equations. The retention curve in Fig. 4 is adopted to describe the gas - liquid pressure equilibrium. Methane is considered as gas species and its properties are evaluated at $20^{\circ} \mathrm{C}$. Table 2 reports the properties adopted in the analyses. Gas exsolution is triggered by means of isotropic unloading under external undrained conditions. The results are reported in Fig. 10 and Fig. 11 in terms of pore liquid pressure and mean soil skeleton stress respectively.

For an initial part of the unloading path until $u_{l}>u_{l / g}$, no gas is exsolved and the decrease in the pore liquid pressure equates the reduction in the mean total stress (i.e. fully saturated response). When the liquid pressure drops below the gas-liquid saturation pressure, gas exsolution and expansion take place and the response starts diverging from that observed in the fully saturated case. At this stage, the decrease in the pore liquid pressure is highly dependent on the relative compressibility of pore fluid-soil skeleton. For stiff soils, the liquid pressure decreases less than for highly compressible soils. As shown in Fig. 10, the pore liquid pressure for $\kappa=0.012$ remains higher than that of the soil having $\kappa=0.09$. This translates into a significant reduction in the mean skeleton stress despite the external undrained conditions. The results displayed in Fig. 11 suggest that stiffer soils may reach the condition $\hat{p} \rightarrow 0$ more likely than softer soils.

Table 2. Material properties and initial variables used in the analyses of gas exsolution.

\begin{tabular}{|l|c|c|}
\hline Parameters & Symbol & Value \\
\hline Slope of ISO-URL & $\kappa$ & $0.09-0.045-0.012$ \\
\hline Initial specific volume & $v_{0}$ & 3 \\
\hline Bulk modulus of water & $K_{w}$ & $2.22 \mathrm{GPa}$ \\
\hline Initial stiffness ratio & $K_{w} / K$ & $667-333-89$ \\
\hline Mean total stress & $p$ & $400 \mathrm{kPa}$ \\
\hline Initial liquid pressure & $u_{l 0}$ & $300 \mathrm{kPa}$ \\
\hline $\begin{array}{l}\text { Gas-liquid saturation } \\
\text { pressure }\end{array}$ & $u_{l / g}$ & $200 \mathrm{kPa}$ \\
\hline
\end{tabular}

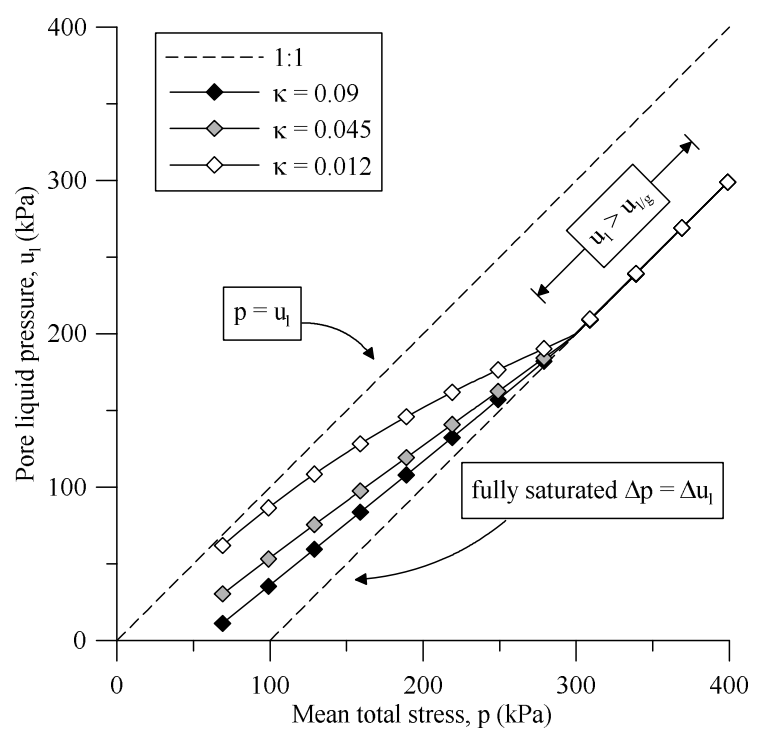

Fig. 10. Evolution of the pore liquid pressure during isotropic undrained unloading of gassy soils.

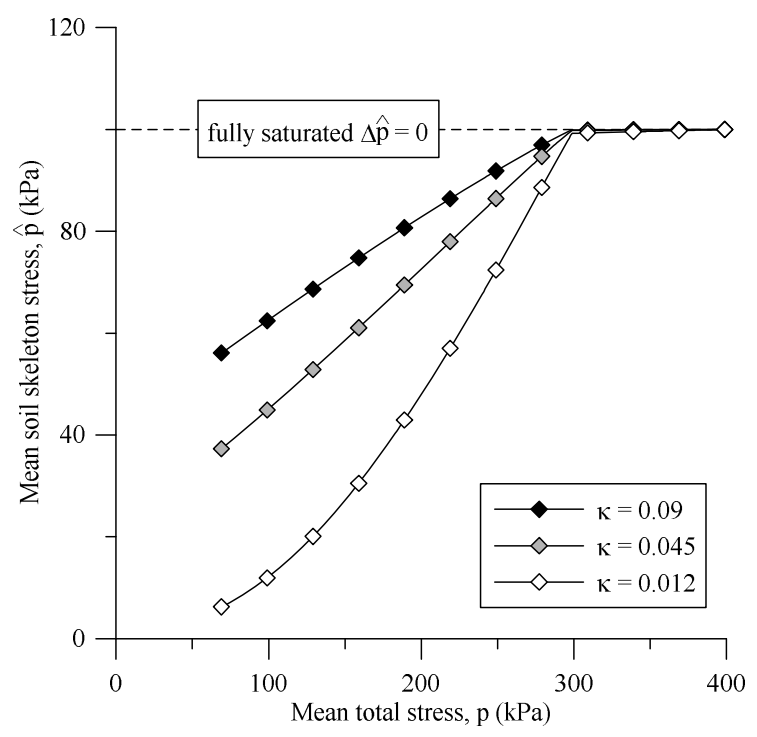

Fig. 11. Evolution of the mean soil skeleton stress during isotropic undrained unloading of gassy soils.

Fig. 12 reports the ratio of the volumetric stiffness of the soil skeleton, $K$, over that of the pore fluid, $K_{f}$, calculated for the mixture of gas and water ([16]):

$$
K=\frac{v \hat{p}}{\kappa}
$$

$$
K_{f}=1 /\left[S_{r} \frac{1}{K_{w}} \frac{\delta u_{l}}{\delta p}+\left(1-S_{r}+S_{r} h\right) \frac{1}{\bar{u}_{g}} \frac{\delta u_{g}}{\delta p}\right]
$$

where $\bar{u}_{g}$ is the absolute gas pressure and $h$ is the Henry's solubility via concentration.

Before gas exsolution takes place, $K_{f}=K_{w}$ and $K / K_{f} \cong 0$. As the gas starts exsolving, the stiffness of the pore fluid decreases. For soft soils, the stiffness ratio is still in favour of the pore fluid and the total stress 
reduction transferred onto the soil skeleton is limited (Fig. 11). On the contrary, for stiffer soils, a small amount of gas is sufficient to increase significantly the stiffness ratio (Fig. 12), causing a small reduction in the pore liquid pressure (Fig. 10). On the one hand, this limits further gas exsolution, as displayed by the high degree of saturation in Fig. 12. On the other hand, it implies that a significant portion of the total stress reduction is transferred onto the soil skeleton (Fig. 11). As soon as the mean soil skeleton stress reduces, the stiffness of the soil skeleton drops dramatically, and the volumetric stiffness ratio starts decreasing in favour of the fluid phase again. Eventually, the limit condition for which $K \rightarrow 0$ is approached, with the stress acting on the soil skeleton tending to zero $\hat{p} \rightarrow 0$. It is worth noting that the stiffer the soil, the lower the amount of gas generated. In the case analysed, the final degree of saturation of the stiffer soil reaches $S_{r}=0.983$, whereas the more compressible soil attains $S_{r}=0.974$.

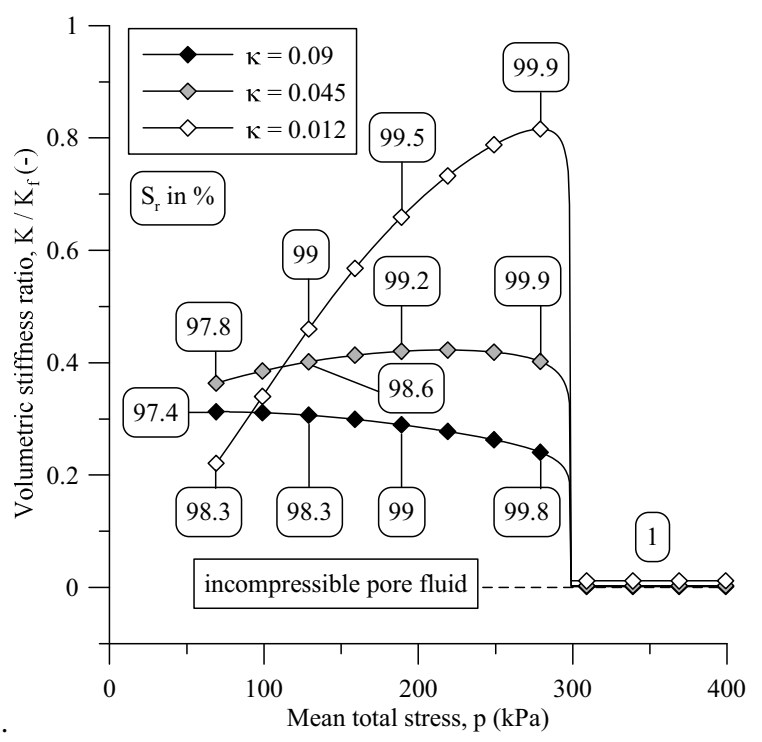

Fig. 12. Evolution of the volumetric stiffness ratio between the soil skeleton and the pore fluid during isotropic undrained unloading of gassy soils.

\section{Conclusions}

The work assesses fully coupled hydro-mechanical numerical approaches developed for unsaturated soils to model the effect of free gas overpressure on the response of peat layers. The presence of gas affects significantly the hydro-mechanical response to external anthropogenic and environmental loads, as several field observations reported. A series of fully coupled two-phase flow with hydro-mechanical coupling numerical analyses were performed accounting for the presence of gas in the soil layer to replicate field observations. The numerical results match qualitatively well the observed field response, confirming that the free gas phase dampens the variation of the pore liquid pressure. However, the magnitude of the pore liquid in excess to the case of fully saturated soils strongly depends on the ratio of the stiffness of the soil skeleton over that of the pore fluid.

For the case of stiff soils as sands, a small amount of gas exsolution increases significantly the stiffness ratio leading to a dramatic reduction in the stress acting on the soil skeleton upon undrained unloading. On the contrary, soft soils as peats are capable to exsolve higher amount of gas before experiencing significant loss of stress. The results of this work are of relevance for future assessment of serviceability and stability analyses of earth embankments founded on peats, where a correct estimation of pore pressure is of primary importance due to the low total stresses experienced by peats.

\section{References}

1. E. J. Den Haan, G. A. M. Kruse. Proc. $2^{\text {nd }}$ Int. Workshop on Characterisation and Engineering of Natural Soils, 29, 2101-2133 (Taylor \& Francis Group, 2007).

2. C. Zwanenburg. Dikes on Peat: analysis of field trials (Internal Report Deltares, 2013).

3. B. F. Vonk. In Advances in understanding and modelling mechanical behaviour of peat, 389-399 (Balkema, Rotterdam, 1994).

4. P. H. Glaser, J. P. Chanton, P. Morin, D. O. Rosenberry, D. I. Siegel, O. Ruud, L. I. Chasar, A. S. Reeve. Global Biogeochem. Cy. 18, 1, 1-15 (2004).

5. E. Kellner, J. M. Waddington, J. S. Price. Water Resour. Res. 41, 8, 1-12 (2005).

6. T. Tokida, T. Miyazaki, M. Mizoguchi. Geophys. Res. Lett. 32, 13 (2005).

7. M. Strack, E. Kellner, J. M. Waddington. Hydrol. Process. 20, 17, 3611-3622 (2006).

8. J. M. Waddington, K. Harrison, E. Kellner, A. J. Baird. Hydrol. Process. 23, 20, 2970-2980 (2009).

9. M. P. Acharya, M. T. Hendry, C. D. Martin. Int. J. Geotech. Eng. 10, 2, 145-154 (2016).

10. C. Jommi, S. Muraro, E. Trivellato, C. Zwanenburg. Géotechnique 69, 9, 753-766 (2019).

11. S. Olivella, A. Gens, J. Carrera, E. E. Alonso. Eng. Computation. 13, 7, 87-112 (1996).

12. E. Trivellato. The effects of partial saturation on the geotechnical properties of peats: an experimental investigation. MSc thesis Politecnico di Milano (2014).

13. M. T. van Genuchten. Soil Sci. Soc. Am. J. 44, 5, 892-898 (1980).

14. R. Sander. Atmospheric Chem. \& Phys. 15, 43994981 (2015).

15. C. Jommi. Experimental evidence and theoretical approaches in unsaturated soils, 139-153 (Balkema Rotterdam, 2000).

16. D. G. Fredlund, H. Rahardjo. Soil mechanics for unsaturated soils (John Wiley \& Sons, 1993). 